\title{
Induction of Protection in Mice against a Chlamydia muridarum Respiratory Challenge by a Vaccine Formulated with the Major Outer Membrane Protein in Nanolipoprotein Particles
}

\author{
Delia F. Tifrea ${ }^{1,+}$, Wei He ${ }^{2,+}{ }^{+}$, Sukumar Pal ${ }^{1}$, Angela C. Evans ${ }^{2}{ }^{(\mathbb{0}}$, Sean F. Gilmore ${ }^{2}$, Nicholas O. Fischer ${ }^{2}$, \\ Amy Rasley ${ }^{2}$, Matthew A. Coleman ${ }^{2,3}$ and Luis M. de la Maza ${ }^{1, *}$ \\ 1 Department of Pathology and Laboratory Medicine, University of California, Irvine, CA 92697, USA; \\ dtifrea@uci.edu (D.F.T.); spal@uci.edu (S.P.) \\ 2 Physical and Life Sciences Directorate, Lawrence Livermore National Laboratory, Livermore, CA 94551, USA \\ he4@llnl.gov (W.H.); evans98@llnl.gov (A.C.E.); gilmore24@llnl.gov (S.F.G.); fischer29@llnl.gov (N.O.F.); \\ rasley2@llnl.gov (A.R.); coleman16@llnl.gov (M.A.C.) \\ 3 School of Medicine, Radiation Oncology, University of California Davis, Sacramento, CA 95616, USA \\ * Correspondence: Imdelama@uci.edu; Tel.: +1-(949)-824-7450; Fax: +1-(949)-824-2160 \\ + These authors contributed equally to this work.
}

Citation: Tifrea, D.F.; He, W.; Pal, S.; Evans, A.C.; Gilmore, S.F.; Fischer, N.O.; Rasley, A.; Coleman, M.A.; de la Maza, L.M. Induction of Protection in Mice against a Chlamydia muridarum Respiratory Challenge by a Vaccine Formulated with the Major Outer Membrane Protein in Nanolipoprotein Particles. Vaccines 2021, 9, 755. https://doi.org/ $10.3390 /$ vaccines 9070755

Academic Editor: Ralph A. Tripp

Received: 26 April 2021

Accepted: 22 June 2021

Published: 7 July 2021

Publisher's Note: MDPI stays neutral with regard to jurisdictional claims in published maps and institutional affiliations.

Copyright: (C) 2021 by the authors Licensee MDPI, Basel, Switzerland. This article is an open access article distributed under the terms and conditions of the Creative Commons Attribution (CC BY) license (https:// creativecommons.org/licenses/by/ $4.0 /)$.

\begin{abstract}
Chlamydia trachomatis is a sexually transmitted bacterium that infects over 130 million individuals worldwide annually. To implement a vaccine, we developed a cell-free co-translational system to express the Chlamydia muridarum major outer membrane protein (MOMP). This approach uses a nanolipoprotein particles (tNLP) made from ApoA1 protein, amphiphilic telodendrimer and lipids that self-assemble to form 10-25 nm discs. These tNLP provide a protein-encapsulated lipid support to solubilize and fold membrane proteins. The cell-free system co-translated MOMP and $A p o A 1$ in the presence of telodendrimer mixed with lipids. The MOMP-tNLP complex was amenable to $\mathrm{CpG}$ and FSL-1 adjuvant addition. To investigate the ability of MOMP-tNLP+CpG+FSL-1 to induce protection against an intranasal (i.n.) C. muridarum challenge, female mice were vaccinated intramuscularly (i.m.) or i.n. and i.m. simultaneously 4 weeks apart. Following vaccination with MOMP-tNLP+CpG+FSL-1, mice mounted significant humoral and cell-mediated immune responses. Following the i.n. challenge, mice vaccinated with MOMP-tNLP+CpG+FSL-1 i.n. + i.m. group were protected as determined by the percentage change in body weight and by the number of $C$. muridarum inclusion forming units (IFU) recovered from the lungs. To our knowledge, this is the first time a MOMP-based vaccine formulated in $\mathrm{tNLP}$ has been shown to protect against $C$. muridarum.
\end{abstract}

Keywords: Chlamydia; vaccine; immunization; mice; nanolipoprotein particles; major outer membrane protein; intranasal challenge; telodisks; amphipols

\section{Introduction}

Chlamydia trachomatis is the leading bacterial sexual transmitted infection (STI) in the world, predominantly affecting young individuals [1]. In the USA it is estimated that more than 3 million new infections occur each year [2]. Multiple infections can occur during a lifetime suggesting that natural infection only induces limited protection [3]. Approximately two thirds of infected women and over 50\% of infected men are asymptomatic [4-7]. In females, $C$. trachomatis acute infections can produce cervicitis and urethritis, while in males, urethritis is the most common acute clinical presentation. Acute and chronic chlamydial infections in females may lead to long-term sequelae including pelvic inflammatory disease (PID), chronic abdominal pain, ectopic pregnancy and infertility [8-10]. In males, epididymites and orchitis are common in young individuals but, so far there is no definitive evidence that they result infertility. Neonates born from mothers that have a genital infection may develop conjunctivitis and severe pneumonia including wheezing, cyanosis and 
tachypnea [10,11]. Respiratory infections have also been described in adults, particularly in those who are immunocompromised [12].

Attempts to control chlamydial infections using screening programs, that included antibiotics treatment, have failed $[13,14]$. Part of the failure of this approach may be due to arrested immunity as a result of antibiotic treatment [14]. These results underscore the need for a vaccine to prevent infection, transmission and disease [15-19]. Indeed, it has long been recognized that even a low efficacy vaccine could have a major impact on the epidemiology of $C$. trachomatis infections [20].

Several proteins, including the major outer membrane protein (MOMP), the chlamydial protease-like activity factor (CPAF), the polymorphic membrane proteins (Pmps) and the plasmid-encoded protein (Pgp3), have been tested as vaccine antigens in genital and respiratory mouse models using $C$. muridarum challenges [15-18]. In the genital model some of these antigens decreased vaginal shedding and inflammatory responses in the upper genital tract [21-23]. However, only recombinant and native MOMP have elicited protection against long-term sequelae, specifically, infertility [24-29].

MOMP is a $40 \mathrm{kDa}$ protein that accounts for the majority of the outer membrane of chlamydial elementary bodies (EB) [30]. When isolated in its native trimeric form, MOMP can induce significant protection against infection and disease in mice [26,31]. This critical native conformation is challenging to recapitulate in recombinant MOMP (rMOMP) [32]. Previously, Olsen et al. [33,34] constructed CTH522, a Cys-free chimeric recombinant C. trachomatis MOMP antigen. CTH522 comprises of C. trachomatis serovar D MOMP and the variable domain 4 (VD4) from serovars D, E, F, and G. [35]. Vaccination with CTH522, adjuvanted with CAF01, induced robust humoral and cell mediated immune responses in mice and protected against vaginal shedding and inflammatory responses in the upper genital tract [33,34]. Protection against hydrosalpinx and/or infertility was not reported. This chimeric recombinant MOMP has now completed Phase 1 clinical trials [36]. However, CTH522 does not fully capture the native structure and oligomeric state of MOMP, which is shown to be of great importance for a chlamydia vaccine. In this study, we sought to address this with a novel formulation.

To optimize the structural and immunogenic properties of recombinant MOMP, He et al. [37] used an NLP comprised of a truncated ApoA1 scaffold protein and lipids that self-assemble to form discs $10-25 \mathrm{~nm}$ in diameter. NLPs provide a membrane-like environment that facilitate embedment of the membrane protein that is functional as well as in its native conformation. C. muridarum MOMP and a truncated ApoA1, 449 ApoA1, were co-translated using T7 plasmids in the presence of lipids and mixed with telodendrimer, an amphiphilic dendrimer [38], to produce water-soluble MOMP-tNLP complexes. These studies demonstrated that this method produced MOMP multimers with similarities to native MOMP [37]. Alternatively, cell-free produced MOMP can also be solubilized by telodisks. Different from tNLPs, telodisks are nanoparticles comprised of only lipids and telodendrimers that are also disc shaped, water soluble and can support membrane proteins. With these approaches we expect that the structure of recombinant MOMP more closely will mimic its native conformation in elementary bodies (EB), the infectious form of Chlamydia and therefore, elicit a more robust protection.

Here, we evaluated immune responses in mice upon vaccination with co-translated MOMP-tNLP and MOMP-telodisk complexed with the Th1 adjuvant CpG-1826 and the Th2 biased adjuvant FSL-1 and investigated its ability to induce protection against an intranasal C. muridarum challenge. In mice, to elicit optimal protection, a subunit chlamydial vaccine, needs to induce $\mathrm{CD}^{+} \mathrm{T}$ cells with Th1-biased cytokines, specially IFN- $\gamma$, and humoral responses, in particular neutralizing antibodies $[15,16,39-41]$. CD8 ${ }^{+} \mathrm{T}$ cells may play a very limited role by secreting IFN- $\gamma$, but they are not cytotoxic $[15,40]$. Here, by including in the formulation adjuvants combinations that elicit both Th1 and Th2 responses, we predicted that protective cellular and humoral responses will be induced. 


\section{Materials and Methods}

\subsection{C. muridarum Stocks}

The C. muridarum strain NiggII (previously called C. trachomatis mouse pneumonitis (MoPn) biovar; American Type Culture Collection, Rockville, MD, USA) was grown in HeLa-229 cells (American Type Culture Collection, Rockville, MD, USA) using Eagle's minimal essential medium supplemented with $5 \%$ fetal calf serum [42]. Elementary bodies (EB) were purified as previously described and stored in sugar phosphate glutamate buffer (SPG) at $-80{ }^{\circ} \mathrm{C}$ [30]. The number of C. muridarum inclusion forming units (IFU) was determined in HeLa-229 cells and the inclusions were stained with a pool of monoclonal antibodies generated in our laboratory [26].

\subsection{Cell-Free Preparation of MOMP-tNLP}

MOMP-tNLPs were prepared using cell-free methods previously described [37]. Briefly, plasmids encoding the codon optimized C. muridarum MOMP gene and His-tagged scaffold $\triangle 49$ ApoA1 gene were added to a $1 \mathrm{~mL}$ RTS 500 ProteoMaster Escherichia coli HY cell-free reaction mixture (Biotechrabbit GmbH, Hannover, Germany) containing 1,2dimyristoyl-sn-glycero-3-phosphocholine (DMPC) (Avanti Polar Lipids, Alabaster, AL, USA) and telodendrimer PEG ${ }^{5 k_{-}} \mathrm{CA}_{8}$. The telodendrimer is a polymer of polyethylene glycol complexed with branched cholate molecules [38]. The reactions were incubated at $30{ }^{\circ} \mathrm{C}$ for $14-18 \mathrm{~h}$. in a floor shaker at $300 \mathrm{rpm}$. The MOMP-tNLP complex was purified by immobilized nickel affinity chromatography using cOmplete His-Tag Purification Resin (Roche Molecular Diagnostics, Basel, Switzerland). Elutions containing MOMP-tNLP were pooled and dialyzed against PBS (pH 7.4). Purified MOMP-tNLP were analyzed by SDSPAGE densitometry for purity and degree of MOMP insertion. Total protein concentration was measured using Qubit (Invitrogen, Carlsbad, CA, USA). To verify molecular weight and concentration of the cell-free produced MOMP, samples were compared to purified rMOMP with known concentration through SDS-PAGE. For a negative control, empty $\mathrm{tNLPs}$ were prepared using the same procedure as that of MOMP-tNLP, except no MOMP encoding DNA was added to the cell-free reaction. Endotoxin levels were checked using the Endosafe ${ }^{\circledR}$-PTS ${ }^{\text {TM }}$ (Charles River, Charleston, SC, USA) endotoxin testing system based on Limulus Amebocyte Lysate (LAL) assay. The average endotoxin level of the MOMP$\mathrm{tNLPs}$ formulations was $7.80 \pm 4.87 \mathrm{EU} / \mu \mathrm{g}$ protein while the average endotoxin level of empty tNLPs was $0.58 \pm 0.14 \mathrm{EU} / \mu \mathrm{g}$ protein.

\subsection{Cell-Free Preparation of MOMP-Telodisk}

MOMP-telodisks were prepared using cell-free methods similar to the preparation of MOMP-tNLP. Briefly, MOMP plasmid was added to a $1 \mathrm{~mL}$ RTS 500 ProteoMaster E. coli $\mathrm{HY}$ cell-free reaction mixture containing DMPC and His-tagged telodendrimer $\mathrm{PEG}^{5 \mathrm{k}}-\mathrm{CA}_{8}-\mathrm{His}$. The reactions were incubated at $30{ }^{\circ} \mathrm{C}$ for $14-18 \mathrm{~h}$. in a floor shaker with shaking at $300 \mathrm{rpm}$. The MOMP-telodisk complex was purified by immobilized nickel affinity chromatography. Elutions containing MOMP-telodisks were pooled and further purified by size exclusion chromatography (SEC) using a Superdex 200 10/300 column (GE Healthcare, Piscataway, NJ, USA) run with PBS buffer $+0.25 \% \mathrm{PEG}_{2000}$. Addition of $0.25 \% \mathrm{PEG}_{2000}$ in PBS was important for effective elution of MOMP-telodisk. Purified MOMP-telodisk concentration was measured using Qubit (Life Technologies, Carlsbad, CA, USA)). Empty telodisks were prepared using the same procedure except without MOMP encoding DNA. Endotoxin levels were checked as above. The average endotoxin level of the MOMP-telodisks formulations was $1.00 \pm 0.76 \mathrm{EU} / \mu \mathrm{g}$ protein.

\subsection{Western Blot and Dot Blot Analyses}

Western blotting and dot blotting were performed using PVDF membranes (MilliporeSigma, Burlington, MA, USA). For Western blotting, samples were resolved with SDS-PAGE. The gels were transferred using the iBlot system (Life Technologies, Carlsbad, CA, USA) according to manufacturer's instructions. Blots were incubated overnight at 
$4{ }^{\circ} \mathrm{C}$ in Odyssey Blocking Buffer (LI-COR Biotechnology, Lincoln, NE, USA) containing

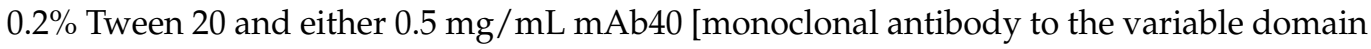
1 (VD1) of MOMP] or $0.2 \mathrm{mg} / \mathrm{mL}$ Penta-His antibody (Qiagen, Hilden, Germany) directed against the ApoA1 His-tag, diluted 1:1000 for mAb40 and 1:500-1:1000 for Penta-His. Blots were washed 3 times for $5 \mathrm{~min}$ with PBS-T (50 mm NaH $\mathrm{PO}_{4}, 300 \mathrm{~mm} \mathrm{NaCl}, 0.2 \%$ Tween 20, pH 7.4) and incubated for $1 \mathrm{~h}$ in blocking buffer containing $1 \mathrm{mg} / \mathrm{mL}$ IRDye 800CW goat (polyclonal) anti-mouse IgG (heavy and light) (LI-COR Biosciences, Lincoln, NE, USA. 1:10,000). Blots were washed again with PBS-T and imaged with a LI-COR FC imager at $800 \mathrm{~nm}$. For dot blots, $3 \mu \mathrm{g}$ of purified MOMP-tNLP and empty tNLP were blotted using the Bio-Dot apparatus (1706545, Bio-Rad, Hercules, CA, USA) according to the manufacturer's instructions. Blots were developed using the same methods described for Western blotting.

\subsection{Adjuvant Addition}

CpG ODN-1826 (Biosearch Technologies, Novato, CA, USA) was custom synthesized with a cholesterol moiety at the $5^{\prime}$ end (referred herein as $\mathrm{CpG}$ ). The insertion of $\mathrm{CpG}$ into NLPs or telodisks is mediated by hydrophobic interactions and has been demonstrated in a previous study [43].

To assess whether the vaccine adjuvant FSL-1 (InvivoGen, San Diego, CA, USA) could be loaded into NLPs, NLPs containing 35\% DGS-NTA(Ni) lipid and 65\% DOPC using recombinantly expressed mouse ApoE4 were prepared as previously described $[43,44]$. Concentration of the purified particles was obtained by measuring the absorbance at $280 \mathrm{~nm}$ using a Nanodrop, and assumes a particle content of 5 scaffold proteins [45]. FSL-1 in water was then added to the NLP solution at the specified FSL-1:NLP ratio and allowed to mix for 30 min. FSL-1:NLP solutions were then analyzed by size exclusion chromatography (SEC) using a Superdex 200 10/300 column (GE Healthcare, Piscataway, NJ, USA) while measuring absorbance of the particle solutions at $214 \mathrm{~nm}$.

During the vaccine preparation, both immune-stimulatory adjuvants CpG and FSL1 were added directly to the purified MOMP-tNLP and empty tNLP at the specified concentration for each group. The adjuvanted samples were analyzed by analytical SEC using Superdex 200, 5/150 GL column, (GE Healthcare, Piscataway, NJ, USA) in PBS buffer $(0.5 \mathrm{~mL} / \mathrm{m}$ in flow rate). The adjuvanted MOMP-tNLP and empty $\mathrm{tNLP}$ were stored at $4{ }^{\circ} \mathrm{C}$ prior to animal use.

\subsection{Purification and Formulation of C. muridarum rMOMP in Amphipols (MOMP/APol)}

The C. muridarum rMOMP was extracted from the $E$. coli inclusion bodies as described by Marston [46]. The pellet of the rMOMP was solubilized in TEN buffer with $8 \mathrm{M}$ urea, $0.1 \mathrm{mM}$ PMSF and $0.02 \mathrm{mM}$ DTT to a concentration of $10 \mathrm{mg} / \mathrm{mL}$. Following solubilization the rMOMP was loaded onto a Sephacryl-S-300 column $(1 \times 50 \mathrm{~cm}$; Sigma-Aldrich, St. Louis, MO, USA), which was pre-equilibrated with $100 \mathrm{mM}$ Tris- $\mathrm{HCl}, \mathrm{pH}$ 8.0, $200 \mathrm{mM}$ $\mathrm{NaCl}, 10 \mathrm{mM}$ EDTA, $0.2 \mathrm{mM}$ DTT, and 0.05\% Z3-14 (Anatrace; Maumee, OH, USA) and the peak fractions were pooled [32]. The apparent MW and purity of C. muridarum rMOMP was determined by 10\% tricine-SDS-PAGE. Using the limulus amoebocyte assay (BioWhittaker, Inc., Walkersville, MD, USA), the rMOMP was found to have less than $0.05 \mathrm{EU}$ of LPS/mg of protein. The rMOMP was transferred from zwittergent Z3-14 to amphipols (APols) A835 (Anatrace, Maumee, OH, USA) by incubation at room temperature for $2 \mathrm{~h}$ at a weight ratio of $1 / 4$ [27,31]. The Z3-14 detergent was removed with rehydrated BioBeads SM-2 Adsorbent (Bio-Rad, Hercules, CA, USA) at a weight ratio of 1/2.5 (Z3-14/Biobeads) by incubation for $16 \mathrm{~h}$ at $4{ }^{\circ} \mathrm{C}$, after which the beads were separated by centrifugation $[27,31]$.

\subsection{Pilot Experiment}

Five-week-old female BALB/c $\left(\mathrm{H}-2^{\mathrm{d}}\right)$ mice were purchased from Charles River Laboratories (Hollister, CA, USA). All mice were maintained at the University of California, Irvine Vivarium and experiments carried out in accordance with the IACUC guidelines. 
To evaluate the safety, reactogenicity and protective ability of MOMP-tNLP and MOMP-telodisk preparations, a pilot study was performed with six groups of mice, seven animals per group. The two experimental groups were: (1) MOMP (10 $\mu \mathrm{g} / \mathrm{mouse} / \mathrm{immuni}$ zation) in Telodisks adjuvanted with CpG (1 $\mu \mathrm{g} /$ mouse/immunization) and (2) MOMP $(10 \mu \mathrm{g} /$ mouse/immunization) in tNLP adjuvanted with CpG (1 $\mu \mathrm{g} /$ mouse/immunization). Mice were immunized twice by the intranasal (i.n.), $20 \mu \mathrm{L} /$ nostril, plus intramuscular (i.m.), $50 \mu \mathrm{L} /$ hind leg, routes at 4 -week intervals. The positive control was vaccinated once i.n. with $10^{4}$ inclusion forming units (IFU) of C. muridarum in $20 \mu \mathrm{L}$ of Eagle's Minimum Essential Medium (EMEM). Two antigen controls and one vaccine negative controls were immunized with: (1) Telodisks plus CpG (1 $\mu \mathrm{g} /$ mouse/immunization); (2) tNLP plus CpG ( $1 \mu \mathrm{g} /$ mouse/immunization); and (3) PBS with $0.25 \% \mathrm{PEG}_{2000}$. The negative controls were immunized using the same protocol as the experimental groups.

Six weeks after the last immunization mice were challenged i.n. with $10^{4}$ C. muridarum IFU. The body weight was determined before the challenge and then daily for 10 consecutive days at which time the animals were euthanized, their lungs harvested, weighed, and the number of C. muridarum IFU determined.

\subsection{Mouse Immunizations}

To assess the effectiveness of MOMP-tNLP adjuvanted with CpG and FSL-1, BALB/c mice were vaccinated twice four weeks apart with $10 \mu \mathrm{g}$ of $C$. muridarum MOMP/mouse/ immunization in tNLP, containing $1 \mathrm{ug}$ of CpG and $1 \mathrm{ug}$ of FSL-1 per mouse/ immunization. A group of mice was vaccinated simultaneously by the i.n., $20 \mu \mathrm{L} /$ nostril, plus i.m., $50 \mu \mathrm{L}$, routes while another group was immunized only i.m., $50 \mu \mathrm{L}$. A positive control received rMOMP $10 \mu \mathrm{g} /$ mouse/immunization, produced in E. coli and adjuvanted with $10 \mu \mathrm{g} / \mathrm{mouse} / \mathrm{imm}$ unization of CpG-1826 (Tri-Link, San Diego, CA, USA) plus Montanide ISA 720 VG (SEPPIC Inc., Fairfield, NJ, USA; 70\% of total vaccine volume) [32]. Montanide ISA 720 VG was delivered only i.m. The second positive control was immunized once i.n. with $10^{4}$ IFU of C. muridarum EB in $20 \mu \mathrm{L}$ of EMEM. Two negative controls were included: one received empty tNLP with adjuvants twice i.n. + i.m. four weeks apart and the other one was inoculated i.n. + i.m. once with $20 \mu \mathrm{L}$ of PBS (pH 7.2). The experiments were replicated once.

\subsection{ELISA Antibody Titers}

Blood was collected the day before the i.n. challenge and C. muridarum specific antibody titers in serum were determined by an ELISA as described [26]. Pre-immunization sera were used as negative controls. In brief, 96-well plates were coated with $100 \mu \mathrm{L}$ of C. muridarum EB at a concentration of $10 \mu \mathrm{g}$ of protein $/ \mathrm{mL}$. In addition, the antibody titers were also determined utilizing MOMP-tNLP as the antigen $(0.1 \mu \mathrm{g} /$ well). Serum was added to each well in 2-fold serial dilutions. After incubation, the plates were washed and incubated with horseradish peroxidase-conjugated goat anti-mouse IgG antibodies (BD Pharmingen, San Diego, CA, USA). The binding was measured in an EIA reader (Labsystem Multiscan, Helsinki, Finland). The geometric mean titers (GMT) are expressed as the reciprocal of the dilution.

\subsection{In Vitro Neutralization Titers}

In vitro neutralization assays were performed as published [47]. C. muridarum $\left(1 \times 10^{4} \mathrm{IFU}\right)$ were added to mice sera and two-fold serial dilutions were made with $\mathrm{Ca}^{2+}$ and $\mathrm{Mg}^{2+}$ free $\mathrm{PBS}$, $\mathrm{pH} 7.2$, supplemented with $5 \%$ guinea pig serum. After incubation for $45 \mathrm{~min}$ at $37{ }^{\circ} \mathrm{C}$, the mixtures were inoculated by centrifugation into HeLa-229 cells grown on shell vials. Following $30 \mathrm{~h}$ of incubation at $37^{\circ} \mathrm{C}$ the monolayers were fixed and stained with a pool of mAbs [48]. The titer of a sample was the dilution that yielded 50\% neutralization relative to the negative control serum from PBS immunized mice. 


\subsection{Cellular Immune Responses}

A T-cell lymphoproliferative assay (LPA) was performed as described [26,31]. Briefly, spleens from mice were collected, teased and enriched for T-cells by passage over a nylon wool column. T-enriched cells $(>95 \%)$ were counted and $10^{5}$ cells $/$ well were aliquoted into a 96-well plate. Antigen presenting cells (APC) were prepared by irradiating splenocytes with 3300 rads. UV inactivated C. muridarum EB were added at a concentration of $5 \mathrm{~EB}$ to 1 APC. MOMP/APol was used at a concentration of $1 \mu \mathrm{g} /$ well. As negative control wells received medium alone and as positive control concanavalin A $(5 \mu \mathrm{g} / \mathrm{mL})$. T-cells were stimulated for $48 \mathrm{~h}$ and levels of IFN- $\gamma$ and IL- 6 were determined in supernatants using commercial kits (BD Pharmingen, San Diego, CA, USA) [49].

\subsection{Evaluation of the Infection Following the i.n. Challenge}

Four weeks after the last immunization anesthetized mice were challenged i.n. with $10^{4} \mathrm{IFU}$ of C. muridarum [32,50]. After the i.n. challenge, mice were weighed for 10 days [32]. At day 10 post-challenge (D10 p.c.) mice were euthanized, their lungs weighed, homogenized and serial 10-fold dilutions were used to infect HeLa-229 cells. Following centrifugation, the plates were incubated for $30 \mathrm{~h}$ at $37^{\circ} \mathrm{C}$ in a $5 \% \mathrm{CO}_{2}$ incubator. Inclusions were stained with a pool of $C$. muridarum-specific $m A$ Abs and were counted [48] using light microscopy. The limit of detection (BLD) was: $<50$ C. muridarum IFU/lungs/mouse.

To determine the local humoral and cellular immune responses in the lungs, the titers of $C$. muridarum-specific IgA and levels of IFN- $\gamma$ in lung's supernatants at D10 p.c. were determined by an ELISA as described [51].

\subsection{Statistical Analyses}

Student's $t$-test was performed to compare antibody ELISA titers and neutralization titers. The Mann-Whitney $U$ test was employed to compare levels of cytokines in spleen supernatants. The Kruskal-Wallis with Dunn's multiple comparisons test was used to compare the number of $C$. muridarum IFU in the lungs, and the one-way ANOVA with Tukey's multiple comparisons test was performed to compare the lungs weight, body weight, and levels of cytokines in the lungs. Repeated measures ANOVA analyses were conducted to compare changes in mean body weight over the 10 days of observation.

\section{Results}

\subsection{Expression, Characterization of MOMP-tNLP and MOMP-Telodisk}

For MOMP-tNLP, the cell-free co-translation reaction resulted in expression of both MOMP and $\triangle 49 A$ poA1, which formed a de novo-soluble complex that was purified through Ni affinity purification. The MOMP concentration was confirmed by direct comparison to purified rMOMP of known concentration via gel densitometry (Figure 1A). The average total affinity purified yield was $1.5 \mathrm{mg}$ MOMP-tNLP complex per $\mathrm{mL}$ reaction. Dot blots of purified MOMP-tNLP and empty tNLP probed with $\mathrm{mAb}-\mathrm{His}$ and $\mathrm{mAb} 40$ showed proper incorporation of MOMP in the tNLPs (Figure 1B). In addition, the purified MOMP within the tNLPs formed higher order oligomers, as demonstrated by Western blot (Figure 1C). In the absence of both heat and reducing agent, bands corresponding to higher order structures were observed (Figure $1 \mathrm{C}$, right lane). These disappeared when samples were heated in the presence of DTT (Figure 1C, left lane). 
A

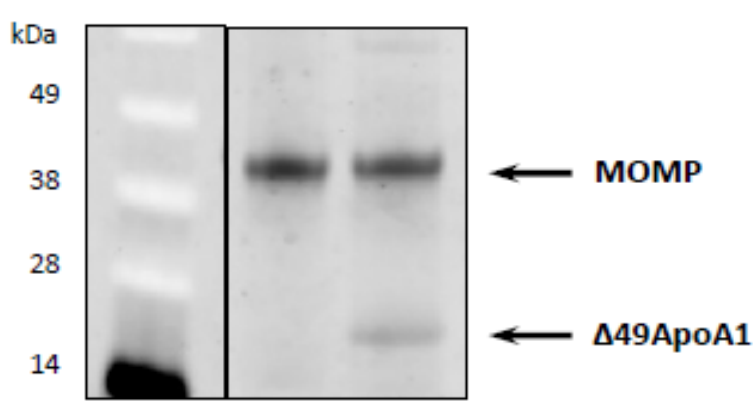

C

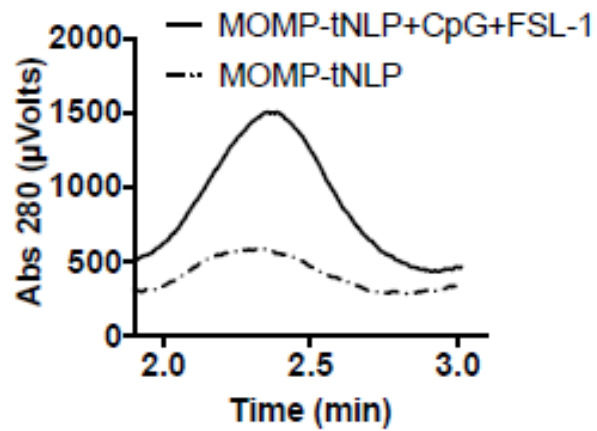

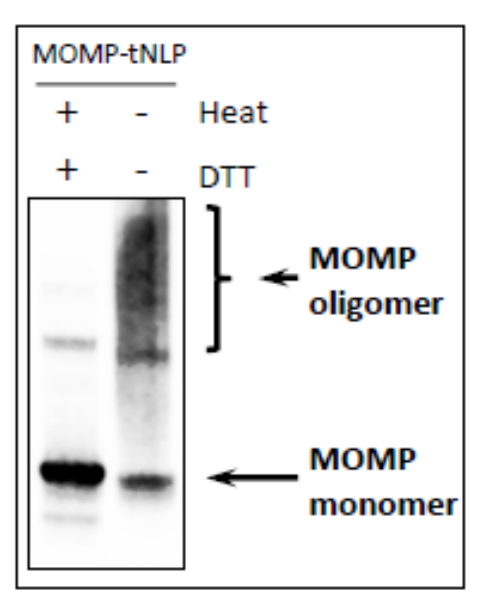

E

Time (min)
B

\section{MOMP-tNLP Empty-tNLP}

mAb40
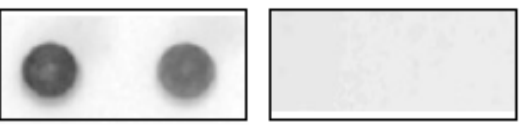

mAbHIS
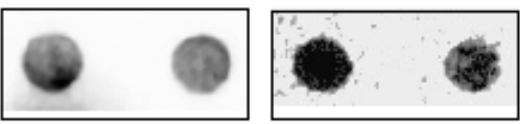

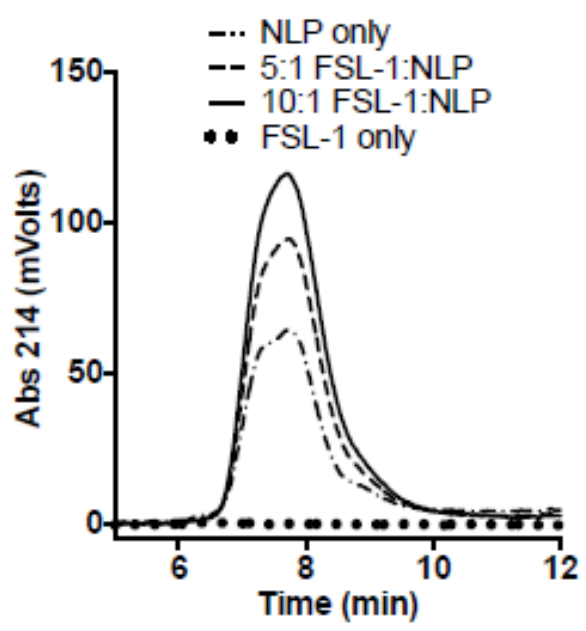

Figure 1. Expression, characterization and adjuvant addition of MOMP-tNLP. (A) SDS-PAGE of purified MOMP-tNLP. Left lane (MW markers) Lane 1: One $\mu \mathrm{g}$ of purified recombinant MOMP. Lane 2: Purified MOMP-tNLP containing one $\mu \mathrm{g}$ of MOMP. The gel densitometry values are: lane 1 top band, 15,971.3; lane 2 top band 15,887.4; lane 2 bottom band 3629.0 (Ana-lyzed by ImageJ). (B) Dot blot of purified MOMP-tNLP and empty tNLP probed with anti-MOMP mAb40, and anti-Histag antibody mAbHIS. Blotting is done in duplicate. Histag is on the N-terminal of tNLP scaffold $\triangle 49 A$ ApoA1. (C) MOMP forms higher order structures in MOMP-tNLPs as analyzed by Western blot. In the right lane, the presence of higher order bands indicates MOMP multimer conformation. In the left lane, heat and denaturant break down higher order MOMP structures (samples were boiled for $5 \mathrm{~min}$ in the presence of $50 \mathrm{mM}$ DTT). The gel densitometry values are: left lane top bands, 841.9; left lane bottom band, 9239.1; right lane top bands 6077.9; right lane bottom band 3643.4 (Analyzed by ImageJ). (D) FSL-1 adjuvant incorporation into NLPs. FSL-1 is a lipopeptide that can be anchored in the NLP bilayer via the acyl chains. SEC demonstrates dose-dependent incorporation of FSL-1, evidenced by an increase in absorbance at $214 \mathrm{~nm}$. (E) SEC traces of MOMP-tNLP particles with and without adjuvant addition. Same amount of MOMP-tNLP were loaded onto SEC. The increase in A280 indicates association of adjuvant CpG with the MOMP-tNLP. 
For MOMP-telodisk, it is also purified by Ni affinity purification after cell-free reactions (Supplementary Figure S1A). Dot blots of purified MOMP-telodisks probed with $\mathrm{mAb}$-His and mAb40 confirmed incorporation of MOMP in the telodisks (Supplementary Figure S1B). The purified MOMP-telodisk also showed higher order oligomers in Western blot in the absence of heat and reducing agent (Supplementary Figure S1C).

\subsection{Adjuvant Addition}

NLPs are known to be excellent carriers for immune adjuvant molecules such as CpG, whereby the cholesterol tag anchors the adjuvant in the NLP bilayer through hydrophobic interactions [43]. This same strategy was used to incorporate the amphipathic lipopeptide FSL-1 into the NLP. NLPs were mixed and incubated with FSL-1 at increasing molar ratios and analyzed by SEC. The adjuvanted NLP complex showed a dose dependent increase in $214 \mathrm{~nm}$ (used to monitor absorption of peptide bonds), indicating successful incorporation of FSL-1 (Figure 1D).

MOMP-tNLP was characterized by SEC after incubation with CpG and FSL-1. The adjuvanted MOMP-tNLP showed a similar retention time compared with the non-adjuvanted MOMP-tNLP. However, the adjuvanted MOMP-tNLP showed a much higher absorption at $280 \mathrm{~nm}$, indicating successful loading of dual adjuvant molecules. The increase in the signal intensity at $280 \mathrm{~nm}$ of the MOMP-tNLP peak is indicative of the binding of CpG, which has a high molar absorptivity (Figure 1E) [43].

\subsection{Pilot Experiment}

Six groups of mice were vaccinated and challenged i.n. with C. muridarum. The MOMP$\mathrm{tNLP}+\mathrm{CpG}$ and the MOMP-telodisk+CpG groups each had its own negative control group without MOMP. In addition, a negative vaccine control group received $\mathrm{PBS}+0.025 \% \mathrm{PEG}_{2000}$ and a positive control group was immunized with viable C. muridarum EB.

After immunization, mice were assessed daily for the appearance of ruffled fur, behavioral changes, decreased mobility or loss of body weight. Mice showed mild signs of distress for 4-5 days and then recovered.

Following the i.n. challenge, positive control mice immunized i.n. with C. muridarum viable EB maintained their body weight over the 10 days of the experiment (Supplementary Figure S2). In contrast, the three negative control groups at day 3 post-challenge (p.c.) rapidly started to lose body weight that continued for the 10 days of the experiment. Over the 10-day period, the experimental group vaccinated with MOMP-telodisk+CpG lost body weight similar to the negative controls. Mice vaccinated with MOMP-tNLP+CpG lost less weight over the 10-day period than the controls immunized with $\mathrm{tNLP}+\mathrm{CpG}$, or the group receiving PBS with $0.25 \% \mathrm{PEG}_{2000}(p<0.05)$.

By D10 p.c. mice vaccinated with MOMP+tNLP+CpG had lost significantly less body weight $(10 \%)$ than the negative control group $(20 \%)(p<0.05)$ (Supplementary Figure S3A). Mice vaccinated with MOMP in Telodisks were not protected when compared with the negative control $(p>0.05)$.

To evaluate the local inflammatory responses elicited by the C. muridarum i.n. challenge, lungs were collected and weighed at D10 p.c. (Supplementary Figure S3B). Typically, unprotected mice have shown increased lungs weight after challenge. The groups vaccinated with MOMP+tNLP+CpG had lighter lungs $(0.28 \mathrm{gr})$, than the negative control immunized with $\mathrm{tNLP}+\mathrm{CpG}(0.31 \mathrm{gr})(p<0.05)$. Mice vaccinated with MOMP-telodisk+CpG $(0.28 \mathrm{gr})$ were not protected when compared with the telodisk $+\mathrm{CpG}$ control (0.30 gr) $(p>0.05)$.

Protection against infection was determined by quantifying the number of C. muridarum IFUs recovered from the lungs at D10 p.c. (Supplementary Figure S3C). Mice vaccinated with $\mathrm{MOMP}+\mathrm{CpG}+\mathrm{tNLP}$ had significantly less $C$. muridarum IFU in their lungs (median, $\left.12 \times 10^{6}\right)$ when compared with the control inoculated with CpG+tNLP $\left(170 \times 10^{6}\right)$ $(p<0.05)$. The group vaccinated with MOMP-telodisks-CpG had similar number of 
IFU $\left(101 \times 10^{6}\right)$ when compared with its respective negative control immunized with CpG+Telodisks $\left(159 \times 10^{6}\right)(p>0.05)$.

The pilot study showed that mice immunized with MOMP-tNLP were better protected from challenge than those immunized with MOMP-telodisks.

\subsection{Characterization of the Humoral Immune Responses Following Vaccination}

Based on the pilot study results, we decided to proceed with MOMP-tNLP to further assess the immune response of the formulation with both CpG and FSL-1 adjuvants. Background control sera were collected prior to immunization. To evaluate humoral immune responses elicited by vaccination, sera were collected prior to challenge. Total IgG levels were quantified using C. muridarum-EB and MOMP-tNLP as antigens. Significantly higher specific IgG GMT were observed when MOMP-tNLP was used as the antigen (Figure 2A). In mice immunized with MOMP-tNLP+CpG+FSL-1 by the i.m. + i.n. routes the MOMP-tNLP specific IgG GMT was 12,800 while for mice immunized by the i.m. route only, the MOMP-tNLP specific IgG GMT was 10,159. The IgG GMT in the positive controls immunized with rMOMP, or EB were 325,100 and 635, respectively. As shown in Figure 2B, levels of antibodies to EB were low in mice immunized with MOMP-tNLP. The highest IgG GMT, 317, was observed in mice vaccinated with MOMP-tNLP+CpG+FSL-1 using the i.m. route only. The GMT in the control groups immunized i.n. with rMOMP or EBs were 51,200 and 25,600, respectively. The negative controls immunized with tNLP+CpG+FSL-1 and the PBS group had IgG titers below the level of detection.

The in vitro neutralization titers in mice immunized with MOMP-tNLP+CpG+FSL1 i.m. + i.n. was 32 and in the group vaccinated only i.m. was 185 (Figure 2C). Mice vaccinated with live EB had a GMT of 2880 and for those immunized with rMOMP it was 1131. Together, these data showed that MOMP-tNLPs induced robust humoral response.

\subsection{Assessment of Cell Mediated Immune (CMI) Responses Following Vaccination}

To determine CMI responses elicited by vaccination, four mice from each group were euthanized $24 \mathrm{~h}$ prior to the i.n. challenge. T-cells were collected from the spleen, processed into a single cell suspension and cultured in the presence of C. muridarum-EB or rMOMP. After $48 \mathrm{~h}$, culture supernatants were harvested and levels of IFN- $\gamma$ and IL-6, as markers of Th1 and Th2 responses, respectively, were quantified using standard ELISA assays (Figure 3). Levels of IFN- $\gamma(\mathrm{pg} / \mathrm{mL})$ in T-cell supernatants from mice immunized with MOMP-tNLP+CpG+FSL-1 i.m. + i.n. and restimulated with EB were significantly higher than the control groups either immunized with empty tNLP or PBS while both levels were significantly lower than rMOMP or EB vaccinated animals. Levels of IL-6 $(\mathrm{pg} / \mathrm{mL})$ were similar for both MOMP-tNLP+CpG+FSL-1 immunized groups (i.m. and i.n. + i.m.). and were significantly lower than the rMOMP or EB vaccinated mice. To conclude, levels of IFN- $\gamma$ and IL-6, although significant in mice immunized with MOMP-tNLP+CpG+FSL-1, were lower than those elicited in mice vaccinated with rMOMP or EB.

\subsection{Changes in Body Weight Following the C. muridarum i.n. Challenge}

To determine the ability of the MOMP-tNLP+CpG+FSL-1 formulations to elicit protective immune responses, mice were i.n. challenged with $C$. muridarum. To assess the systemic effects of the challenge, the body weight of each mouse was determined for 10 consecutive days.

As shown in Figure 4, the positive control immunized i.n. with C. muridarum EB lost $\sim 3 \%$ of their initial mean body weight by day 4 (D4) after which animals recovered their initial body weight. The group vaccinated with rMOMP lost body weight until D4 and then maintained the weight. Mice immunized with MOMP-tNLP+CpG+FSL-1 i.m. + i.n. lost $\sim 12 \%$ of their initial body weight by D4 and then maintained their body weight until D10. In contrast, animals that received $\mathrm{tNLP}+\mathrm{CpG}+\mathrm{FSL}-1$ continuously lost weight over the 10-day time course. Control animals inoculated with PBS lost the most weight during the 10 days of monitoring similar to mice immunized only i.m. with MOMP-tNLP+CpG+FSL-1. 

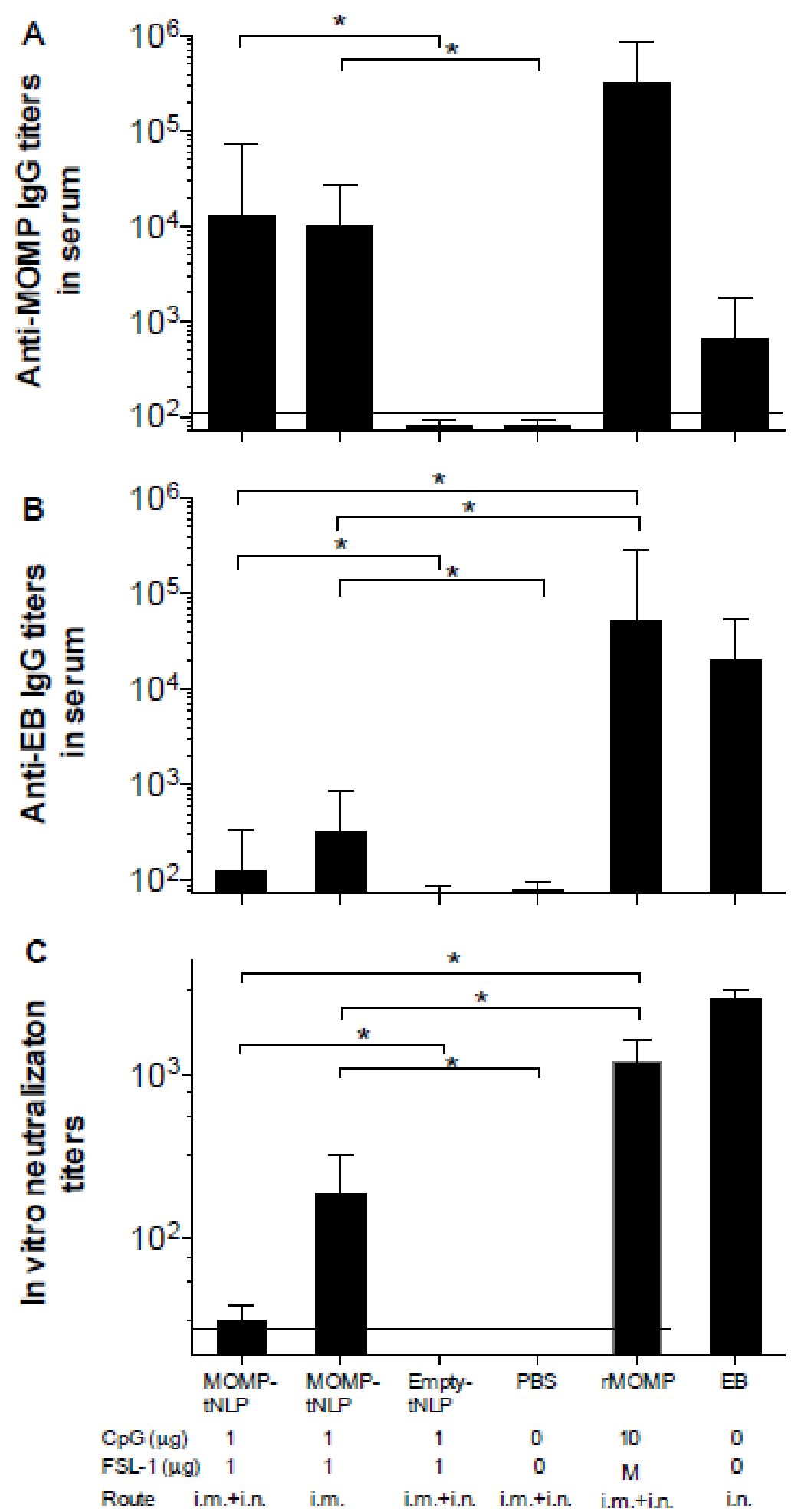

Experimental groups

Figure 2. Serum antibody titers. (A) Anti-C. muridarum MOMP and (B) anti-C. muridarum EB IgG antibody titers. (C) In vitro neutralizing C. muridarum EB titers. Serum samples were collected before immunization as background control, and antibody titers were determined the day before the i.n. challenge. Horizontal dotted lines represent the limit of detection. ${ }^{*} p<0.05$ by ANOVA. 
A

$\square$ MOMP stimulated $\quad \square$ EB stimulated
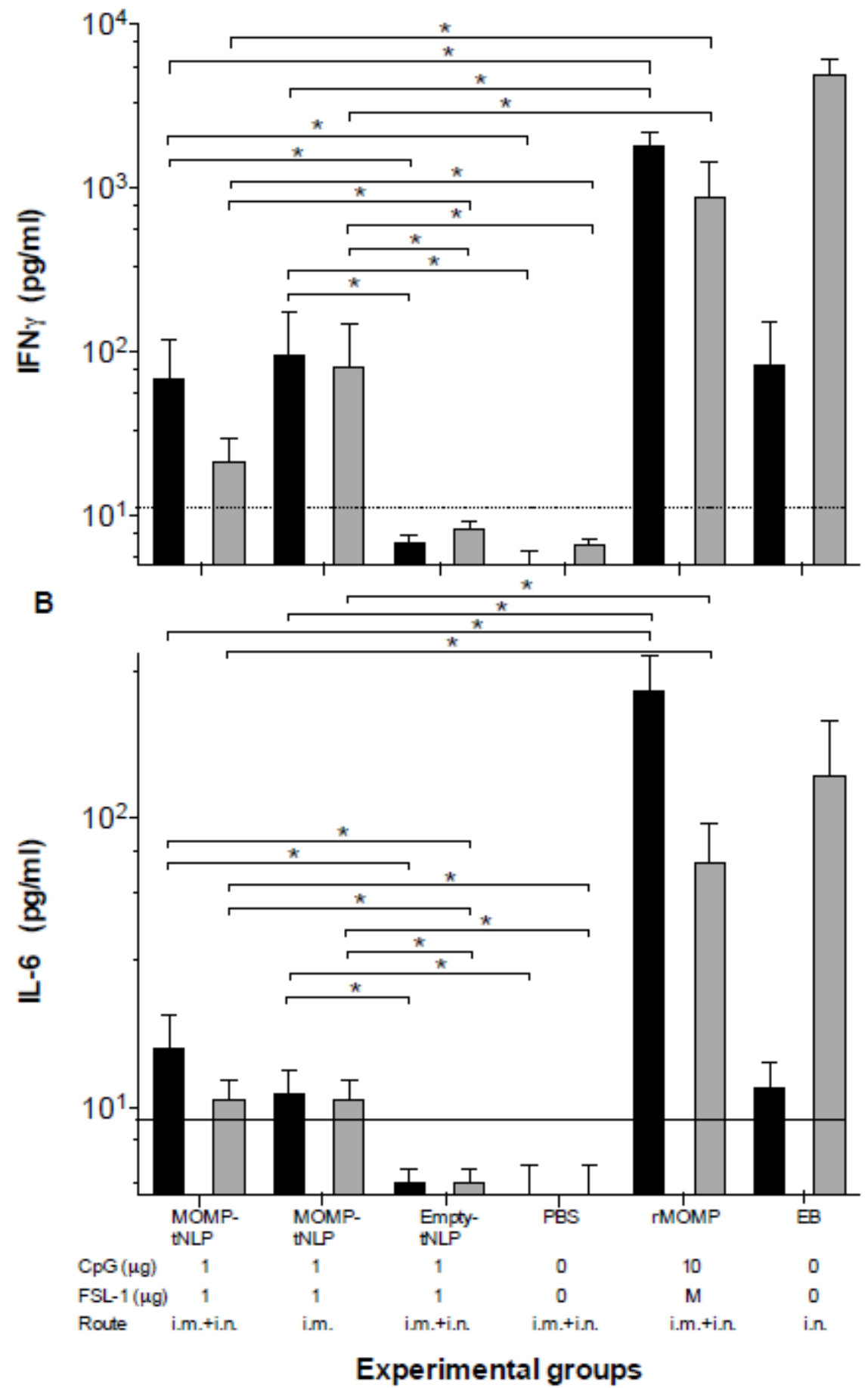

Figure 3. Levels of (A) IFN- $\gamma$ and (B) IL-6 produced by T cells stimulated with EB or MOMP/APols the day before the $C$. muridarum i.n. challenge. The day before the challenge, mice were euthanized, their spleens collected, and T-cells purified using a nylon wool column. Purified T-cells were stimulated in vitro with C. muridarum-EB or with -rMOMP in APols. Cytokines were measure in the tissue culture supernatants. Horizontal dotted line represents the limit of detection. ${ }^{*} p<0.05$ by ANOVA. 


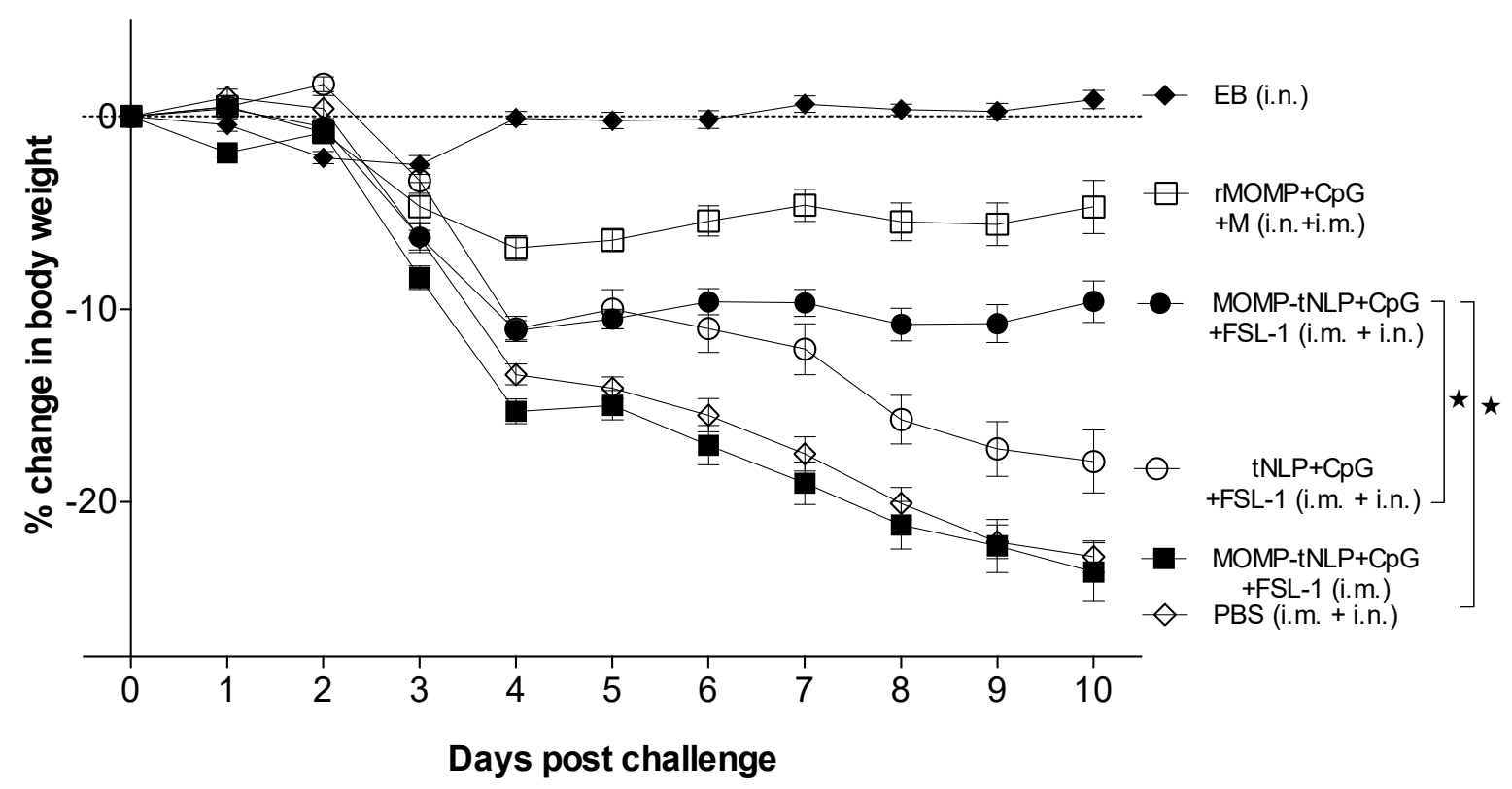

Figure 4. Daily percentage change in mean body weight following the i.n. challenge. ${ }^{*} p<0.05$ by the Repeated Measures 2-way ANOVA.

Based on body weight changes at D10 post-challenge (p.c.) mice vaccinated with MOMP-tNLP+CpG+FSL-1 via the i.m. + i.n. routes $(-9.60 \% ; p<0.05)$ exhibited significant protection when compared to the control tNLP+CpG+FSL-1 immunized animals $(-17.90 \%)$ (Figure 5A). However, the group immunized only i.m. was not protected $(-23.63 \%$; $p>0.05)$ compared to the PBS immunized group. The group vaccinated with rMOMP lost $5 \%$ of their initial body weight while the PBS group lost $23.03 \%$. Mice immunized with EB regained their original body weight.

\subsection{Lungs' Weight}

Mice vaccinated with MOMP-tNLP+CpG+FSL-1, by i.m. + i.n. routes, had statistically lower lungs weight compared to the group immunized by the i.m. route only. Nevertheless, there was no statistical difference in the lungs weight between any of the groups when compared with negative controls immunized with tNLP+CpG+FSL-1 or PBS $(p>0.05)$ (Figure 5B). Lungs weights in mice immunized with rMOMP- or EB-indicated robust protection.

\subsection{Number of C. muridarum IFU Recovered from the Lungs}

Based on the number of IFU recovered (median $15.7 \times 10^{6}$ ), mice immunized i.m. + i.n. with MOMP-tNLP+CpG+FSL-1 were the best protected. This number was significantly lower when compared with mice vaccinated only i.m. $\left(2843 \times 10^{6}\right)$ and the negative control immunized with tNLP+CpG+FSL-1 $\left(1560 \times 10^{6}\right)(p<0.05)$. The group of mice vaccinated with $\mathrm{rMOMP}$ had $1.2 \times 10^{6} \mathrm{IFU}$. No IFU were recovered from the positive control immunized i.n. with EB (limit of detection < $50 \mathrm{IFU} /$ mouse/lungs) (Figure 5C).

\subsection{Local Immune Responses in the Lungs at D10 p.c.}

As an additional parameter to evaluate the local control of the infection, levels of IFN- $\gamma$ were determined in lung supernatants (Figure 6A). Of the groups vaccinated with MOMP-tNLP+CpG+FSL-1, the lowest levels of IFN- $\gamma(1538 ;$ mean $\mathrm{pg} / \mathrm{mL})$ were observed in mice immunized by a combination of i.m. + i.n. routes, significantly lower than the PBS control (3002; $p<0.05)$. Very low levels of IFN- $\gamma$ were observed in the positive control immunized with EB (32), indicative of local control of the infection, while high levels of IFN- $\gamma$ were detected in the groups vaccinated with MOMP-tNLP+CpG+FSL-1 by the i.m. route only and the negative controls immunized with tNLP+CpG+FSL-1 or PBS (2431, 
2613 and 3002, respectively). The level of IFN- $\gamma$ in mice vaccinated with rMOMP was 1077; $p<0.05)$
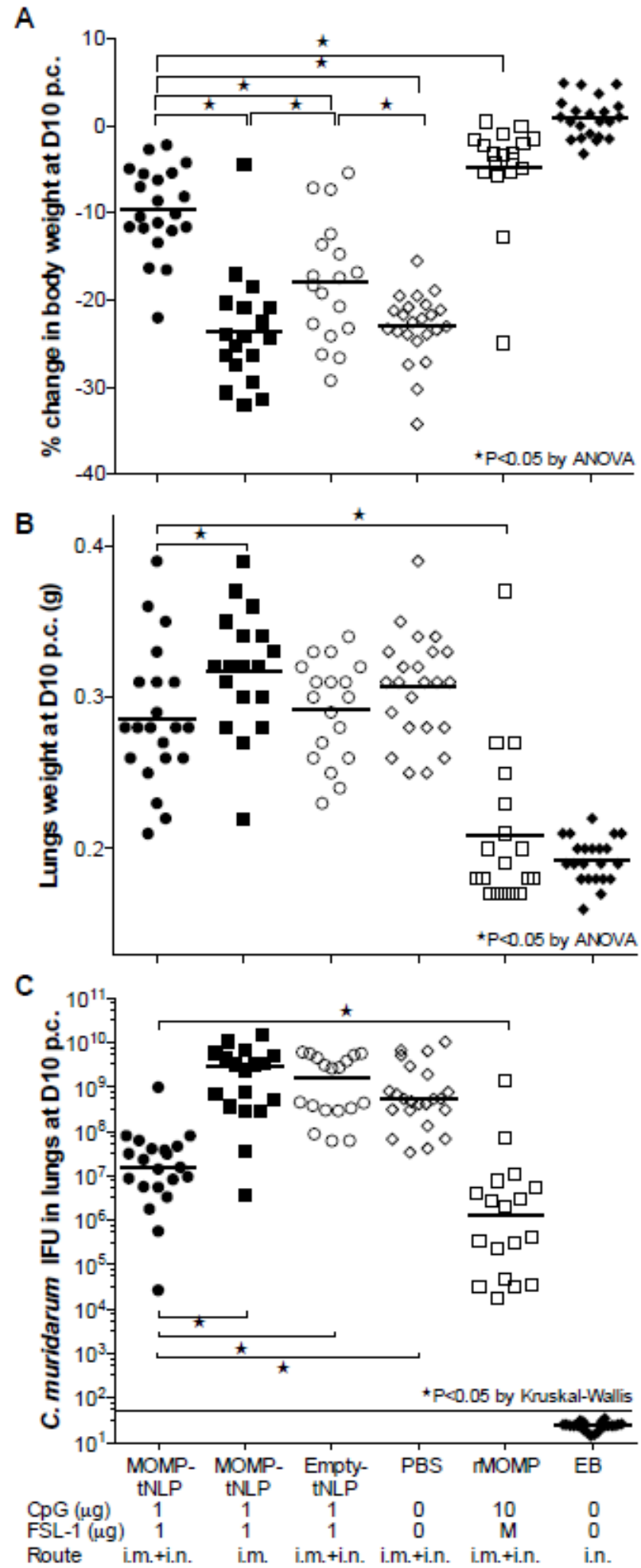

Figure 5. Systemic and local disease burden following the i.n. challenge with C. muridarum. (A) Percentage change in mean body weight at D10 following the i.n. challenge. The mean is shown as a horizontal line. Each symbol represents a single animal. (B) Lungs weight (g) at D10 after the i.n. challenge. The mean is shown as a horizontal line. Each symbol represents a single animal. (C) Number of C. muridarum IFU recovered from the lungs at D10 after the i.n. challenge. The median is shown as a horizontal line. Each symbol represents a single animal. ${ }^{*} p<0.05$. 


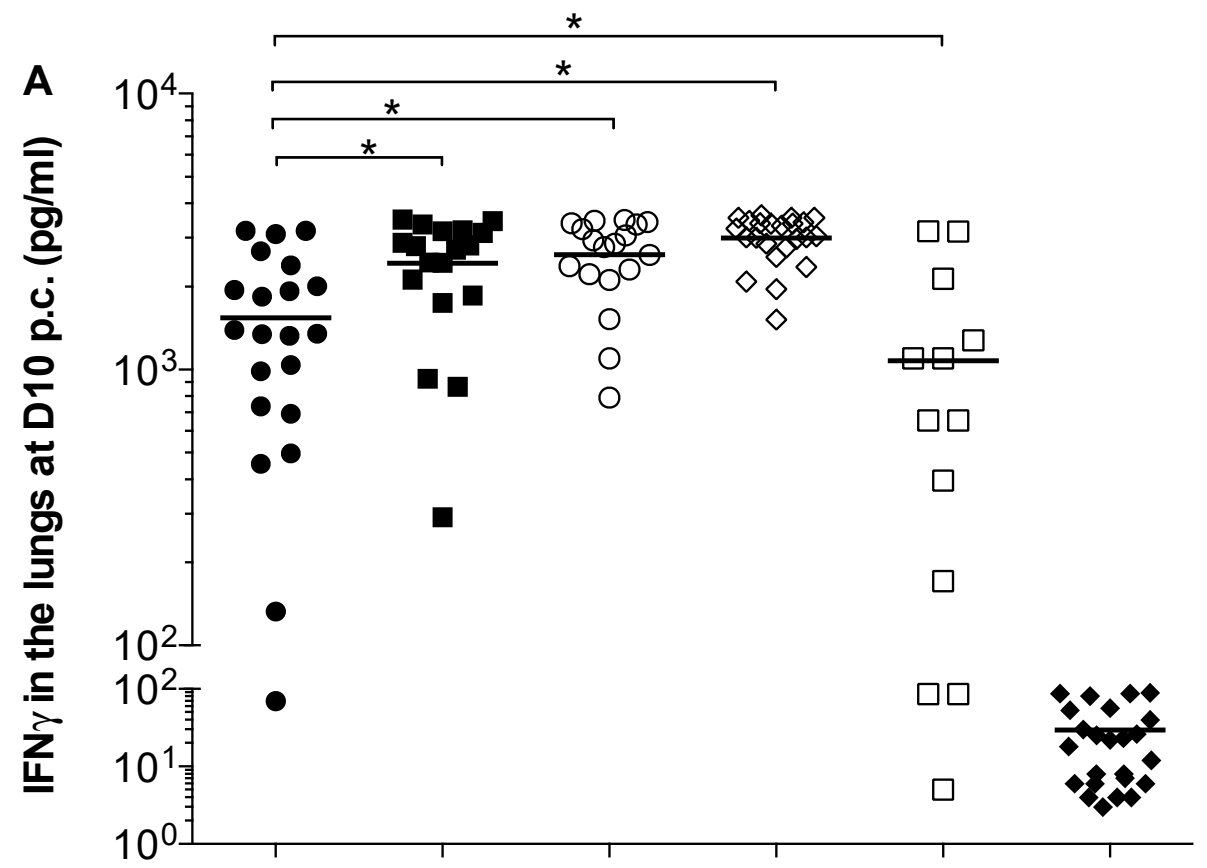

B

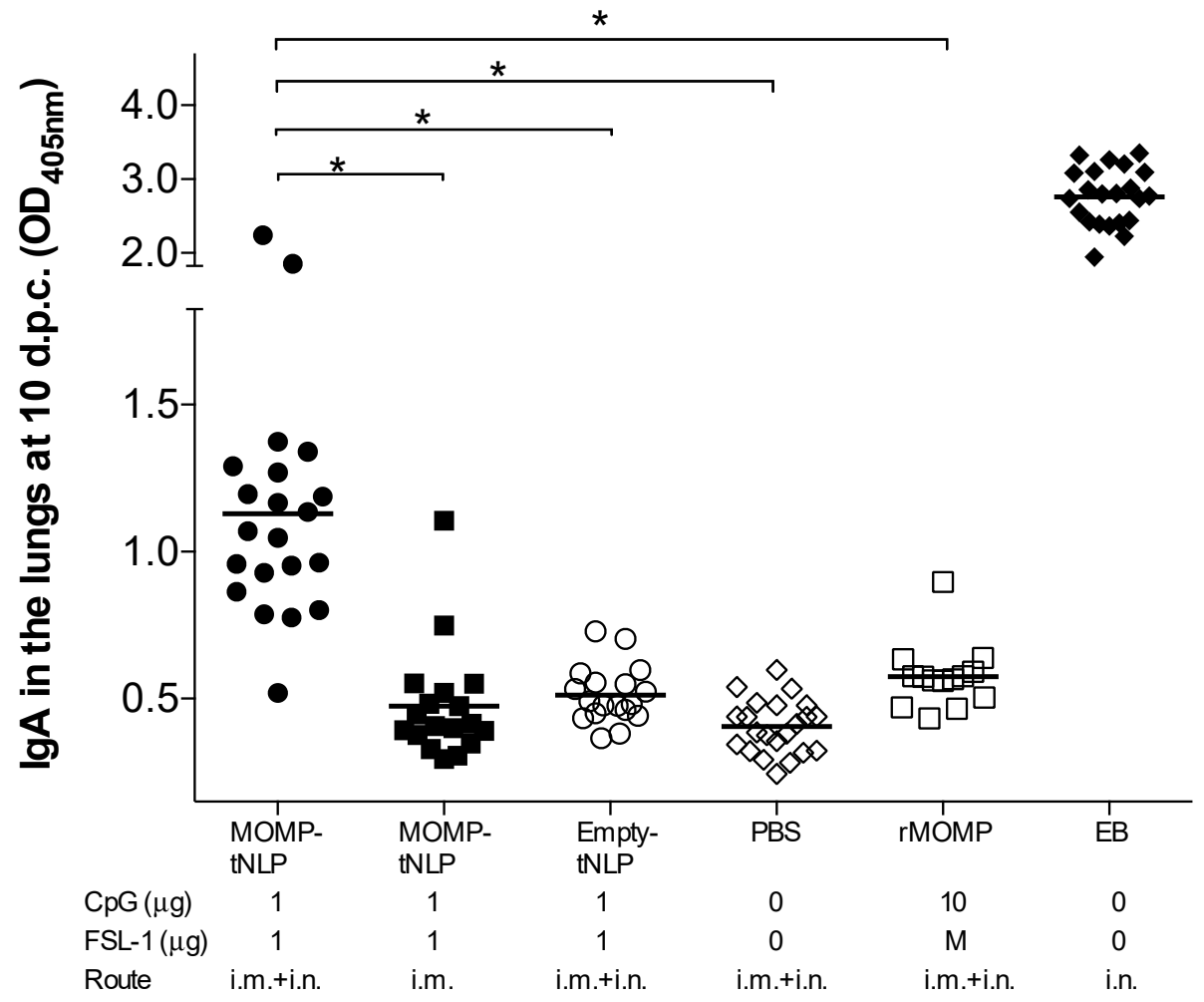

\section{Experimental groups}

Figure 6. Levels of IFN- $\gamma$ and titers of C. muridarum-specific IgA in the lungs at D10 p.c. (A) Levels of IFN- $\gamma(\mathrm{pg} / \mathrm{mL})$ detected in lung supernatants at D10 after the i.n. challenge. The mean is shown as a horizontal line. Each symbol represents a single animal. (B) Levels of $C$. muridarum-specific $\operatorname{IgA}\left(\mathrm{OD}_{405}\right)$ detected in lung supernatants at D10 following i.n. challenge. The mean is shown as a horizontal line. Each symbol represents a single animal. ${ }^{*} p<0.05$.

As a parameter of the local memory immune responses elicited by vaccination, levels of specific C. muridarum IgA were quantified in lungs supernatants (Figure 6B). Mice vaccinated with MOMP-tNLP+CpG+FSL-1 by the i.m. + i.n. routes had higher IgA levels 
(1.130; mean $\left.\mathrm{OD}_{405}\right)$ than those vaccinated only i.m. (0.475) $(p<0.05)$. Mice vaccinated with rMOMP had an IgA level of 0.575. The highest levels of IgA were observed in control mice immunized i.n. with live EBs (2.763) while the lowest level was determined in the negative PBS control (0.405).

\section{Discussion}

The number of $C$. trachomatis infections continues to increase, and there is an urgent need to implement a vaccine. Here, NLPs were used to support and deliver recombinant C. muridarum MOMP by mucosal and systemic routes using CpG and FSL-1 as adjuvants. The cell-free approach allowed for production, purification, and adjuvant addition within a single day to rapidly produce formulations for screening. Some of the vaccine formulations elicited significant humoral and cellular immune responses to $C$. muridarum EB and rMOMP. Mice were subsequently challenged in the nostrils and, based on changes in body weight and number of $C$. muridarum IFU recovered from the lungs, mice were partially protected. Specifically, when mice were simultaneously immunized through i.m. and i.n. routes, the MOMP tNLP vaccine elicited protection, highlighting the importance of the choice of routes. To our knowledge, this is the first time that $C$. muridarum MOMP formulated in a bio-mimetic nanoparticle has been shown to elicit significant protection against infection and disease.

MOMP accounts for $60 \%$ of the outer membrane mass of Chlamydia elementary bodies and is highly antigenic [52]. B-cell epitopes have been mapped to all four variable domains (VDs) of MOMP while T-cell epitopes have been mainly identified in the constant domains (CDs), although some of them were also located in the VDs $[35,53,54]$. Native MOMP can be generated in small quantities, but escalating production to vaccinate humans will be technically difficult and costly. Recombinant MOMP, although not as efficacious at eliciting protection as native MOMP, can easily be produced in E. coli. However, since MOMP is an intrinsic membrane protein, it requires detergents or amphipols to keep it soluble in an aqueous solution [25,31]. The presence of eight cysteine residues in MOMP also creates challenges to obtain an antigen that has consistent structural and antigenic properties.

To evaluate the safety, reactogenicity, and protective ability of tNLP- and telodiskMOMP preparations, a pilot study was performed. Except for the group inoculated with PBS all mice lost body weight following the i.n. plus i.m. immunization. By 4-5 days post-immunization, the animals had recovered their initial body weight and behaved normally. No significant differences between the five groups were observed.

Following challenge, as determined by changes in body weight, lung weight and number of $C$. muridarum IFU recovered from the lungs, mice vaccinated in MOMP-tNLP were better protected than those immunized with MOMP-telodisks. tNLP differs from telodisk by the presence of scaffold proteins which corral the disk shape membrane and further stabilize as well as solubilize the embedded membrane protein [38]. The advantage of tNLP over telodisk is likely due to the increased solubilization and stbility that the tNLP scaffold protein provided to maintain the native state MOMP. Based on these results, we decided to proceed using MOMP-tNLP rather than MOMP-telodisks for the definitive experiments.

The tNLPs were used to keep MOMP soluble and to fold it under conditions that mimic the lipid bilayer of a membrane. Previous results showed that the tNLP supporting scaffold could solubilize MOMP in an oligomeric form as a functional porin [37]. Furthermore, the proper insertion of MOMP into the NLP lipid bilayer should allow for the maximum exposure of the MOMP extracellular domains, including all of the antigenic VDs. An additional benefit of NLP is that they can be used to incorporate a variety of adjuvants for screening vaccine formulations. Using highly purified proteins as vaccine antigens requires the addition of adjuvants to boost local innate and adaptive immune responses [55]. Moreover, co-delivery of adjuvants along with the antigen increases the efficacy of vaccines [56,57]. There is evidence from both human and animal studies that cellular immunity, with Th1 responses and IFN-y production, is needed to recover from in- 
fection. In the mouse model, $\mathrm{CD} 4 \mathrm{~T}$ cells are required for protection against a $C$. muridarum challenge, while CD8 T cells do not seem to play a major role in protection [58]. IFN-y was likely produced by $\mathrm{CD} 4^{+} \mathrm{T}$ cells, and not by $\mathrm{CD} 8^{+} \mathrm{T}$ cells, since they are predominant in the female genital tract [59]. In addition, during re-infection, antibodies control the initial bacterial load and aid in resolution of the infection $[40,58]$. Furthermore, in humans, an inverse correlation has been found between shedding of $C$. trachomatis and immunoglobulin A (IgA) levels in cervical secretions [60]. Thus, to formulate the MOMP-tNLP vaccine we used a combination of CpG, a TLR-9 agonist that elicits Th1 immune responses, and FSL-1, a TLR-2 agonist that induces Th2-biased responses.

Here, mice that were vaccinated using a combination of a mucosal (i.n.) and systemic (i.m.) routes were better protected than the animals immunized only i.m. The utilization of a mucosal immunization route appears to be relevant for protection against mucosal pathogens such as Chlamydia $[27,28,61]$. Determining the best mucosal route for immunization is important not only for eliciting the strongest protection but for ease of use, cost, safety, and societal acceptance. The i.n. route combined with i.m. immunization has been shown to induce mucosal IgA and stimulate immunity not only in local tissues but also in the respiratory and genital tracts [27,28,61]. For example, Ralli-Jain et al. [61] reported that vaccination with recombinant MOMP, combining mucosal and systemic routes, provides enhanced protection against a $C$. muridarum respiratory challenge when compared with protocols using only mucosal or systemic routes for immunization. Similar results were also seen with influenza [62].

\section{Conclusions}

We have shown that $C$. muridarum MOMP formulated in tNLPs, with a combination of a Th1 and a Th2 adjuvant that was delivered by mucosal and systemic routes, elicits humoral and cell-mediated immune responses that partially protect mice against a respiratory challenge. This approach may be used for the formulation of other membrane protein-based vaccines, as the tNLP platform may help promote the formation of native conformation of recombinantly expressed membrane proteins and enhance membrane protein solubility. tNLPs are also highly amenable to co-localized delivery of antigens and adjuvants.

Supplementary Materials: You can find supplementary materials in the attachment online at https: //www.mdpi.com/article/10.3390/vaccines9070755/s1. Figure S1: Purification and characterization of MOMP-telodisk; Figure S2: Changes in body weight following the i.n. challenge; Figure S3: Changes in body weight, lungs weight and number of C. muridarum IFU recovered from the lungs a D10 following the i.n. challenge; Figure S4: Full figures of gel and western blot images.

Author Contributions: D.F.T. planned and conducted experiments, performed data analyses, generated figures and tables and composed manuscript. Approved final version of the manuscript. W.H. contributed to experimental design, data collection and interpretation of the work. He also helped with writing and editing/revising of the manuscript. Approved final version of the manuscript. S.P. performed experiments, analyzed data and revised manuscript. Approved final version of the manuscript. A.C.E. conducted experiments for acquiring the data as well as interpretation of the work. She also helped with editing/revising of the manuscript. Approved final version of the manuscript. S.F.G. conducted experiments for acquiring the data as well as interpretation of the work. He also helped with editing/revising of the manuscript. Approved final version of the manuscript. N.O.F. contributed to design and interpretation of the work. He also helped with writing and editing/revising of the manuscript. Approved final version of the manuscript. A.R. contributed to design and interpretation of the work. She also helped with writing and editing/revising of the manuscript. Approved final version of the manuscript. M.A.C. contributed to the conception and design as well as interpretation of the work. He also helped with writing and editing of the manuscript. Approved final version of the manuscript. L.M.d.l.M. conceived the original idea, supervised the project, interpreted the results and wrote the manuscript. Approved final version of the manuscript. All authors have read and agreed to the published version of the manuscript. 
Funding: This research was funded by Public Health Service grant R21 AI20925 and U19 AI144184 from the National Institute of Allergy and Infectious Diseases. This work was performed under the auspices of the U.S. Department of Energy by Lawrence Livermore National Laboratory under Contract DE-AC52-07NA27344.

Institutional Review Board Statement: These studies were approved by the University of California, Irvine, Institutional Animal Care and Use Committee (IACUC, AUP 20-054, approval period 13 Ju1y 2020-13 July 2023).

Informed Consent Statement: Not applicable.

Data Availability Statement: Data is contained within the article or supplementary material.

Conflicts of Interest: The authors declare no conflict interests.

\begin{abstract}
Abbreviations
Amphipols (Apols); antigen presenting cells (APC); Chlamydia (C.); constant domain (CD); day 1 post-challenge (D1 p.c.); dithiothreitol (DTT); elementary bodies (EB); enzyme linked immunosorbent assay (ELISA); geometric mean titer (GMT); inclusion forming units (IFU); intranasal (i.n.); intramuscular (i.m.); lymphoproliferative assay (LPA); major outer membrane protein (MOMP); telodendrimer nanolipoprotein particles (tNLP); size exclusion chromatography (SEC); sodium dodecyl sulfate-polyacrylamide gel electrophoresis (SDS-PAGE); variable domain (VD).
\end{abstract}

\title{
References
}

1. Newman, L.; Rowley, J.; Vander Hoorn, S.; Wijesooriya, N.S.; Unemo, M.; Low, N.; Stevens, G.; Gottlieb, S.; Kiarie, J.; Temmerman, M. Global estimates of the prevalence and incidence of four curable sexually transmitted infections in 2012 based on systematic review and global reporting. PLoS ONE 2015, 10, e0143304. [CrossRef]

2. CDC. Sexually transmitted disease surveillance 2019. In Prevention; U.S. Department of Health and Human Services: Atlanta, GA, USA, 2021; pp. 1-168.

3. Geisler, W.M.; Lensing, S.Y.; Press, C.G.; Hook, E.W., 3rd. Spontaneous resolution of genital Chlamydia trachomatis infection in women and protection from reinfection. J. Infect. Dis. 2013, 207, 1850-1856. [CrossRef]

4. Stamm, W. Chlamydia trachomatis infections of the adult. In Sexually Transmitted Diseases; Holmes, P.S., Stamm, W.E., Piot, P., Wasserheit, J.W., Corey, L., Cohen, M.S., Watts, D.H., Eds.; McGrawHill Book Co.: New York, NY, USA, 2008 ; pp. $575-593$.

5. Brunham, R.C.; Paavonen, J. Reproductive system infections in women: Lower genital tract syndromes. Pathog. Dis. 2020, 78. [CrossRef]

6. Brunham, R.C.; Paavonen, J. Reproductive system infections in women: Upper genital tract, fetal, neonatal and infant syndromes. Pathog. Dis. 2020, 78. [CrossRef] [PubMed]

7. Schachter, J.; Dawson, C.R. Human Chlamydial Infections; PSG Pub. Co.: Littleton, MA, USA, 1978; pp. xi, 273.

8. Haggerty, C.L.; Gottlieb, S.L.; Taylor, B.D.; Low, N.; Xu, F.; Ness, R.B. Risk of sequelae after Chlamydia trachomatis genital infection in women. J. Infect. Dis. 2010, 201 (Suppl. 2), S134-S155. [CrossRef] [PubMed]

9. Westrom, L.; Joesoef, R.; Reynolds, G.; Hagdu, A.; Thompson, S.E. Pelvic inflammatory disease and fertility. A cohort study of 1844 women with laparoscopically verified disease and 657 control women with normal laparoscopic results. Sex. Transm. Dis. 1992, 19, 185-192. [CrossRef] [PubMed]

10. Darville, T. Recognition and treatment of chlamydial infections from birth to adolescence. Adv. Exp. Med. Biol. 2013, 764, 109-122. [PubMed]

11. Numazaki, K.; Asanuma, H.; Niida, Y. Chlamydia trachomatis infection in early neonatal period. BMC Infect. Dis. 2003, 3, 2. [CrossRef]

12. Cunha, B.A. The chlamydial pneumonias. Drugs Today 1998, 34, 1005-1012. [CrossRef]

13. Gotz, H.; Lindback, J.; Ripa, T.; Arneborn, M.; Ramsted, K.; Ekdahl, K. Is the increase in notifications of Chlamydia trachomatis infections in Sweden the result of changes in prevalence, sampling frequency or diagnostic methods? Scand. J. Infect. Dis. 2002, 34, 28-34. [CrossRef]

14. Brunham, R.C.; Pourbohloul, B.; Mak, S.; White, R.; Rekart, M.L. The unexpected impact of a Chlamydia trachomatis infection control program on susceptibility to reinfection. J. Infect. Dis. 2005, 192, 1836-1844. [CrossRef]

15. Farris, C.M.; Morrison, R.P. Vaccination against Chlamydia genital infection utilizing the murine C. muridarum model. Infect. Immun. 2011, 79, 986-996. [CrossRef]

16. de la Maza, L.M.; Zhong, G.; Brunham, R.C. Update on Chlamydia trachomatis vaccinology. Clin. Vaccine Immunol. 2017, 24. [CrossRef] [PubMed]

17. Zhong, G.; Brunham, R.C.; de la Maza, L.M.; Darville, T.; Deal, C. National Institute of Allergy and Infectious Diseases workshop report: "Chlamydia vaccines: The way forward". Vaccine 2017. [CrossRef] [PubMed]

18. Phillips, S.; Quigley, B.L.; Timms, P. Seventy years of Chlamydia vaccine research-Limitations of the past and directions for the future. Front. Microbiol. 2019, 10, 70. [CrossRef] [PubMed] 
19. Gottlieb, S.L.; Deal, C.D.; Giersing, B.; Rees, H.; Bolan, G.; Johnston, C.; Timms, P.; Gray-Owen, S.D.; Jerse, A.E.; Cameron, C.E.; et al. The global roadmap for advancing development of vaccines against sexually transmitted infections: Update and next steps. Vaccine 2016, 34, 2939-2947. [CrossRef] [PubMed]

20. de la Maza, M.A.; de la Maza, L.M. A new computer model for estimating the impact of vaccination protocols and its application to the study of Chlamydia trachomatis genital infections. Vaccine 1995, 13, 119-127. [CrossRef]

21. Murthy, A.K.; Chambers, J.P.; Meier, P.A.; Zhong, G.; Arulanandam, B.P. Intranasal vaccination with a secreted chlamydial protein enhances resolution of genital Chlamydia muridarum infection, protects against oviduct pathology, and is highly dependent upon endogenous gamma interferon production. Infect. Immun. 2007, 75, 666-676. [CrossRef]

22. Yu, H.; Karunakaran, K.P.; Jiang, X.; Brunham, R.C. Evaluation of a multisubunit recombinant polymorphic membrane protein and major outer membrane protein $\mathrm{T}$ cell vaccine against Chlamydia muridarum genital infection in three strains of mice. Vaccine 2014, 32, 4672-4680. [CrossRef]

23. Donati, M.; Sambri, V.; Comanducci, M.; Di Leo, K.; Storni, E.; Giacani, L.; Ratti, G.; Cevenini, R. DNA immunization with pgp3 gene of Chlamydia trachomatis inhibits the spread of chlamydial infection from the lower to the upper genital tract in $\mathrm{C} 3 \mathrm{H} / \mathrm{HeN}$ mice. Vaccine 2003, 21, 1089-1093. [CrossRef]

24. Pal, S.; Ausar, S.F.; Tifrea, D.F.; Cheng, C.; Gallichan, S.; Sanchez, V.; de la Maza, L.M.; Visan, L. Protection of outbred mice against a vaginal challenge by a Chlamydia trachomatis serovar $\mathrm{E}$ recombinant major outer membrane protein vaccine is dependent on phosphate substitution in the adjuvant. Hum. Vaccines Immunother. 2020. [CrossRef]

25. Pal, S.; Theodor, I.; Peterson, E.M.; de la Maza, L.M. Immunization with the Chlamydia trachomatis mouse pneumonitis major outer membrane protein can elicit a protective immune response against a genital challenge. Infect. Immun. 2001, 69, 6240-6247. [CrossRef]

26. Pal, S.; Peterson, E.M.; de la Maza, L.M. Vaccination with the Chlamydia trachomatis major outer membrane protein can elicit an immune response as protective as that resulting from inoculation with live bacteria. Infect. Immun. 2005, 73, 8153-8160. [CrossRef] [PubMed]

27. Carmichael, J.R.; Pal, S.; Tifrea, D.; de la Maza, L.M. Induction of protection against vaginal shedding and infertility by a recombinant Chlamydia vaccine. Vaccine 2011, 29, 5276-5283. [CrossRef] [PubMed]

28. Tifrea, D.F.; Pal, S.; de la Maza, L.M. A recombinant Chlamydia trachomatis MOMP vaccine elicits cross-serogroup protection in mice against vaginal shedding and infertility. J. Infect. Dis. 2020, 221, 191-200. [CrossRef] [PubMed]

29. Pal, S.; Cruz-Fisher, M.I.; Cheng, C.; Carmichael, J.R.; Tifrea, D.F.; Tatarenkova, O.; de la Maza, L.M. Vaccination with the recombinant major outer membrane protein elicits long-term protection in mice against vaginal shedding and infertility following a Chlamydia muridarum genital challenge. NPJ Vaccines 2020, 5, 90. [CrossRef]

30. Caldwell, H.D.; Kromhout, J.; Schachter, J. Purification and partial characterization of the major outer membrane protein of Chlamydia trachomatis. Infect. Immun. 1981, 31, 1161-1176. [CrossRef]

31. Tifrea, D.F.; Pal, S.; Popot, J.L.; Cocco, M.J.; de la Maza, L.M. Increased immunoaccessibility of MOMP epitopes in a vaccine formulated with amphipols may account for the very robust protection elicited against a vaginal challenge with Chlamydia muridarum. J. Immunol. 2014, 192, 5201-5213. [CrossRef]

32. Sun, G.; Pal, S.; Weiland, J.; Peterson, E.M.; de la Maza, L.M. Protection against an intranasal challenge by vaccines formulated with native and recombinant preparations of the Chlamydia trachomatis major outer membrane protein. Vaccine 2009, 27, 5020-5025. [CrossRef]

33. Olsen, A.W.; Follmann, F.; Erneholm, K.; Rosenkrands, I.; Andersen, P. Protection against Chlamydia trachomatis infection and upper genital tract pathological changes by vaccine-promoted neutralizing antibodies directed to the VD4 of the major outer membrane protein. J. Infect. Dis. 2015. [CrossRef]

34. Olsen, A.W.; Lorenzen, E.K.; Rosenkrands, I.; Follmann, F.; Andersen, P. Protective effect of vaccine promoted neutralizing antibodies against the intracellular pathogen Chlamydia trachomatis. Front. Immunol. 2017, 8, 1652. [CrossRef]

35. Baehr, W.; Zhang, Y.X.; Joseph, T.; Su, H.; Nano, F.E.; Everett, K.D.; Caldwell, H.D. Mapping antigenic domains expressed by Chlamydia trachomatis major outer membrane protein genes. Proc. Natl. Acad. Sci. USA 1988, 85, 4000-4004. [CrossRef]

36. Abraham, S.; Juel, H.B.; Bang, P.; Cheeseman, H.M.; Dohn, R.B.; Cole, T.; Kristiansen, M.P.; Korsholm, K.S.; Lewis, D.; Olsen, A.W.; et al. Safety and immunogenicity of the chlamydia vaccine candidate CTH522 adjuvanted with CAF01 liposomes or aluminium hydroxide: A first-in-human, randomised, double-blind, placebo-controlled, phase 1 trial. Lancet Infect. Dis. 2019, 19, 1091-1100. [CrossRef]

37. He, W.; Felderman, M.; Evans, A.C.; Geng, J.; Homan, D.; Bourguet, F.; Fischer, N.O.; Li, Y.; Lam, K.S.; Noy, A.; et al. Cell-free production of a functional oligomeric form of a Chlamydia major outer-membrane protein (MOMP) for vaccine development. $J$. Biol. Chem. 2017, 292, 15121-15132. [CrossRef] [PubMed]

38. He, W.; Luo, J.; Bourguet, F.; Xing, L.; Yi, S.K.; Gao, T.; Blanchette, C.; Henderson, P.T.; Kuhn, E.; Malfatti, M.; et al. Controlling the diameter, monodispersity, and solubility of ApoA1 nanolipoprotein particles using telodendrimer chemistry. Protein Sci. A Publ. Protein Soc. 2013, 22, 1078-1086. [CrossRef] [PubMed]

39. Yu, H.; Karunakaran, K.P.; Jiang, X.; Brunham, R.C. Subunit vaccines for the prevention of mucosal infection with Chlamydia trachomatis. Expert Rev. Vaccines 2016, 15, 977-988. [CrossRef]

40. Farris, C.M.; Morrison, S.G.; Morrison, R.P. CD4+ T cells and antibody are required for optimal major outer membrane protein vaccine-induced immunity to Chlamydia muridarum genital infection. Infect. Immun. 2010, 78, 4374-4383. [CrossRef] [PubMed] 
41. Morrison, S.G.; Morrison, R.P. A predominant role for antibody in acquired immunity to chlamydial genital tract reinfection. J. Immunol. 2005, 175, 7536-7542. [CrossRef]

42. Nigg, C. An unidentified virus which produces pneumonia and systemic infection in mice. Science 1942, 95, 49-50. [CrossRef]

43. Weilhammer, D.R.; Blanchette, C.D.; Fischer, N.O.; Alam, S.; Loots, G.G.; Corzett, M.; Thomas, C.; Lychak, C.; Dunkle, A.D.; Ruitenberg, J.J.; et al. The use of nanolipoprotein particles to enhance the immunostimulatory properties of innate immune agonists against lethal influenza challenge. Biomaterials 2013, 34, 10305-10318. [CrossRef]

44. Weilhammer, D.; Dunkle, A.D.; Blanchette, C.D.; Fischer, N.O.; Corzett, M.; Lehmann, D.; Boone, T.; Hoeprich, P.; Driks, A.; Rasley, A. Enhancement of antigen-specific CD4(+) and CD8(+) T cell responses using a self-assembled biologic nanolipoprotein particle vaccine. Vaccine 2017, 35, 1475-1481. [CrossRef]

45. Blanchette, C.D.; Law, R.; Benner, W.H.; Pesavento, J.B.; Cappuccio, J.A.; Walsworth, V.; Kuhn, E.A.; Corzett, M.; Chromy, B.A.; Segelke, B.W.; et al. Quantifying size distributions of nanolipoprotein particles with single-particle analysis and molecular dynamic simulations. J. Lipid Res. 2008, 49, 1420-1430. [CrossRef]

46. Marston, F.A. The purification of eukaryotic polypeptides synthesized in Escherichia coli. Biochem. J. 1986, 240, 1-12. [CrossRef]

47. Peterson, E.M.; Zhong, G.M.; Carlson, E.; de la Maza, L.M. Protective role of magnesium in the neutralization by antibodies of Chlamydia trachomatis infectivity. Infect. Immun. 1988, 56, 885-891. [CrossRef] [PubMed]

48. Pal, S.; Fielder, T.J.; Peterson, E.M.; de la Maza, L.M. Protection against infertility in a BALB/c mouse salpingitis model by intranasal immunization with the mouse pneumonitis biovar of Chlamydia trachomatis. Infect. Immun. 1994, 62, 3354-3362. [CrossRef] [PubMed]

49. Tifrea, D.F.; Sun, G.; Pal, S.; Zardeneta, G.; Cocco, M.J.; Popot, J.L.; de la Maza, L.M. Amphipols stabilize the Chlamydia major outer membrane protein and enhance its protective ability as a vaccine. Vaccine 2011, 29, 4623-4631. [CrossRef] [PubMed]

50. Cheng, C.; Jain, P.; Bettahi, I.; Pal, S.; Tifrea, D.; de la Maza, L.M. A TLR2 agonist is a more effective adjuvant for a Chlamydia major outer membrane protein vaccine than ligands to other TLR and NOD receptors. Vaccine 2011, 29, 6641-6649. [CrossRef] [PubMed]

51. Cheng, C.; Pal, S.; Tifrea, D.; Jia, Z.; de la Maza, L.M. A vaccine formulated with a combination of TLR-2 and TLR-9 adjuvants and the recombinant major outer membrane protein elicits a robust immune response and significant protection against a Chlamydia muridarum challenge. Microbes Infect. 2014, 16, 244-252. [CrossRef]

52. Caldwell, H.D.; Schachter, J. Antigenic analysis of the major outer membrane protein of Chlamydia spp. Infect. Immun. 1982, 35, 1024-1031. [CrossRef]

53. Stephens, R.S.; Wagar, E.A.; Schoolnik, G.K. High-resolution mapping of serovar-specific and common antigenic determinants of the major outer membrane protein of Chlamydia trachomatis. J. Exp. Med. 1988, 167, 817-831. [CrossRef]

54. Ortiz, L.; Angevine, M.; Kim, S.K.; Watkins, D.; DeMars, R. T-cell epitopes in variable segments of Chlamydia trachomatis major outer membrane protein elicit serovar-specific immune responses in infected humans. Infect. Immun. 2000, 68, 1719-1723. [CrossRef]

55. Harandi, A.M.; Davies, G.; Olesen, O.F. Vaccine adjuvants: Scientific challenges and strategic initiatives. Expert Rev. Vaccines 2009, 8, 293-298. [CrossRef]

56. Blander, J.M.; Medzhitov, R. Toll-dependent selection of microbial antigens for presentation by dendritic cells. Nature 2006, 440, 808-812. [CrossRef]

57. Fischer, N.O.; Rasley, A.; Corzett, M.; Hwang, M.H.; Hoeprich, P.D.; Blanchette, C.D. Colocalized delivery of adjuvant and antigen using nanolipoprotein particles enhances the immune response to recombinant antigens. J. Am. Chem. Soc. 2013, 135, $2044-2047$. [CrossRef] [PubMed]

58. Morrison, S.G.; Morrison, R.P. Resolution of secondary Chlamydia trachomatis genital tract infection in immune mice with depletion of both CD4+ and CD8+ T cells. Infect. Immun. 2001, 69, 2643-2649. [CrossRef] [PubMed]

59. Kelly, K.A.; Walker, J.C.; Jameel, S.H.; Gray, H.L.; Rank, R.G. Differential regulation of CD4 lymphocyte recruitment between the upper and lower regions of the genital tract during Chlamydia trachomatis infection. Infect. Immun. 2000, 68, 1519-1528. [CrossRef] [PubMed]

60. Brunham, R.C.; Kuo, C.C.; Cles, L.; Holmes, K.K. Correlation of host immune response with quantitative recovery of Chlamydia trachomatis from the human endocervix. Infect. Immun. 1983, 39, 1491-1494. [CrossRef] [PubMed]

61. Ralli-Jain, P.; Tifrea, D.; Cheng, C.; Pal, S.; de la Maza, L.M. Enhancement of the protective efficacy of a Chlamydia trachomatis recombinant vaccine by combining systemic and mucosal routes for immunization. Vaccine 2010, 28, 7659-7666. [CrossRef]

62. Hasegawa, H.; Ichinohe, T.; Strong, P.; Watanabe, I.; Ito, S.; Tamura, S.; Takahashi, H.; Sawa, H.; Chiba, J.; Kurata, T.; et al. Protection against influenza virus infection by intranasal administration of hemagglutinin vaccine with chitin microparticles as an adjuvant. J. Med. Virol. 2005, 75, 130-136. [CrossRef] 